\title{
A CORROBORATIVE APPROACH FOR ENGINEERING EDUCATION USING DESIGN THINKING
}

\author{
Govil Alok $^{1}$, Pillalamarri Saipriya ${ }^{2}$ \\ ${ }^{1}$ Department of Civil Engineering, S R Engineering College, Warangal, Telangana, India \\ ${ }^{2}$ Department of Civil Engineering, S R Engineering College, Warangal, Telangana, India \\ 1alok_govil@srecwarangal.ac.in \\ ${ }^{2}$ pillalamarrisaipriya@gmail.com
}

\begin{abstract}
As we move ahead in the present world, a gradual downfall in the Engineering education has been significantly seen due to various reasons, be it Methodology, Approach or Pedagogy. Due to the overwhelming demand for Quality Education, many techniques have been evolved such as Active Learning and Collaborative Learning Techniques. Yet there is a wide-open gap to successfully attain the objectives of Engineering Education. In order to bridge the Gap, a tool namely Design Thinking has been introduced which acts as a complementary tool for Engineering to Work on. Design thinking is a methodology that involves lateral thinking in order to identify and solve the problems in a strategic way. The paper enshrines the role of Design thinking and its aspects in Engineering Education.
\end{abstract}

Keywords: Design Thinking, User-Centric Design, Prototype, Multidisciplinary, Engineering Education

\begin{abstract}
Govil Alok
Department of Civil Engineering,

S R Engineering College, Warangal, Telangana, India

alok_govil@srecwarangal.ac.in

\section{Introduction}

Design Thinking along with its attributes are becoming the key element in the field of Engineering. Toady every aspect in the field of engineering emphasizes greatly on Design Thinking. It is a well-known fact that Design thinking has redefined many commercial, business and IT industries. Yet delivering it to students and making them aware and understand about it has become crucial [1]. Students are to be exposed in a real-time scenario rather than in a virtual world so that they grab user experience and have lucid experience in generating viable solutions [2]. Design Thinking, on one hand, provides scope for sustenance whereas engineering brings hands-on experience in order to develop a prototype. This together brings out an excellent environment for students to serve the Users and their communities at large to solve their real-time problems [3]. Design Thinking involves many stages from Identification to Development. The Generic Design Thinking Stages can be named as Empathize, Define, Ideate, Prototype, Test [4]. These stages are based on the Lateral Thinking Approach which enumerates various tools within them.
\end{abstract}

\section{Challenges in Engineering Education}

It is indeed necessary to review the current status of higher education assessment activities and propose a comprehensive process that will eventually lead to the development and acceptance by key stakeholders of a framework for a spectrum of activities appropriate to the engineering education enterprise and to the individual missions of engineering colleges [5], Basically Engineering Education faces many crucial challenges such as Practical / Industrial Awareness, Communication, Employment, Ethical Awareness, Sustainability, Methodology, Funding, General Awareness, Curriculum and many more. One shall imply smart planning which includes five characteristics i.e. Specific, Measurable, Attainable, Relevant and Time-based. 


\section{Integrated Multidisciplinary Approach}

One of the keys to overcoming challenges is by combining several disciplines or professional specializations in a significant way in order to provide complex solutions by redefining the problems and finding ample, adequate and sustainable solutions. In general, multidisciplinary integrated work is often seen as a game-changer by the specialists, but in general, it is just a simple fundamental expression. However, fewer times such integrations have bought certain complexities in function and order among the works with the public interests. When it comes to multidisciplinary tasks, fields like engineering, technology, education, construction, etc., are all certainly involved. For instance in the case of multidisciplinary studies, students and institution have choice to design their educational programs which suits their own interests along with their career goals [6]. It can be significantly helpful for considering the curriculum, requirements, and career transforming possibilities.

\section{Design Thinking - Course Overview}

A course namely design Thinking and Innovation was introduced as an elective to the Students to provide them with the Techniques to deal with real world problems in a properly manifested and effective way. The details of the course are as follows:

\section{A. Basic Information}

The following basic Information with the program is as shown below

\begin{tabular}{|l|l|}
\hline \multicolumn{2}{|c}{ Table 1. Basic Course Information } \\
\hline Branch & All Branches \\
\hline Prerequisite & III Year \\
\hline Credits & Product Design Studio \\
\hline No. of Lectures & 3 \\
\hline No. of Weeks & 3 Hours Per Week \\
\hline No. of Instructors & 14 \\
\hline Continuous Internal Evaluation & $\begin{array}{l}\text { 50 Marks } \\
\text { Students }\end{array}$ \\
\hline Semester End Examination & $\mathbf{5 0}$ Marks \\
\hline
\end{tabular}

B. Course Objectives and Outcomes

Course Objectives:

Students will be able to

1. Define the need for creative and design thinking.

2. Recognize various discovery phases and insights in idea generation.

3. Prepare the Idea generation concept.

4. Experiment with the group project work by using various techniques.

5. Evaluate the delivery phase and prototyping.

\section{Course Outcomes:}

At the end of the course, the students will be able to,

1. Recall various creative and design thinking models.

2. Convert ideas into future products/services.

3. Discover new ideas through team workshops.

4. Compare the difference between concept visualization and prototyping.

5. Produce prototypes based on design thinking.

6. Setup new stranded in converting raw ideas into reality.

7. Define how to build customer relations.

8. Summarize the importance and need for creative and design thinking.

C. Design Thinking - Process

The Design thinking Tool is a process that involves various stages to effective transfer the abilities in order to bring out the best solutions for the Problems. The stages and its importance are briefly explained with a real-time studentinstructor work for better understanding.

\section{a. Empathize}

Empathy is very important to understand the true and realistic need of a user. It is usually observed that many times the true problems or more definitive needs aren't spoken. In order to understand the true needs of the user, various techniques are used to Empathize with the user. Observation, shadowing, Experiencing and Interviewing are the basic tools that are used herein Design Thinking in order to empathize with the Users.

\section{i) Job Platform}

Have a keen observation on the work done by the surveyors/students in the field. Especially during the construction projects and estimations, their role is primary. Being a major part of their work, it is an essential part to carry the required instruments into the field where ever they go. In that case, many problems raised only while carrying the instruments required to the field.

\section{ii) Tasks Flow}

Instruments being part of surveyors/students work in the field, it's very essential to think of the major problem faced by them. Surveyors/students generally make the measurements and dimensioning with respective instruments in order to fulfill the survey. To conduct a survey, a minimum of 5 people are required in order to finish the experiment and even to carry experiments. Where in which technology has improved and TOTAL STATION came into existence. Even though, the minimum requirement to conduct a survey is 2 people. So, these problems would be kept in mind and go ahead with the fruitful solution wherein which surveyors/students shouldn't face problem in conducting the survey or even while carrying the instruments.

\section{iii) Observation}

It is based on something one has seen, heard or noticed [7]. Eg: I have observed my classmates going to survey camp with few instruments and tools. 


\section{iv) Interaction}

As we have chosen our domain as SURVEY IN THE FIELD, there must be some interaction done with the students or surveyors and other site engineers if possible. In that case, we started interacting with college students about the job they are actually doing and what are their experiences, then discussed about the problems and few solutions came out of it too

\section{v) Experience}

Our experience talking to the students in the field is better than the best. Gathered many people over there and it has become easy for to know everything about the task what they are actually doing. The way they replied for our doubts and the way they communicated made our day. It might be at work but, it is actually good making some new friends at the end of the day.
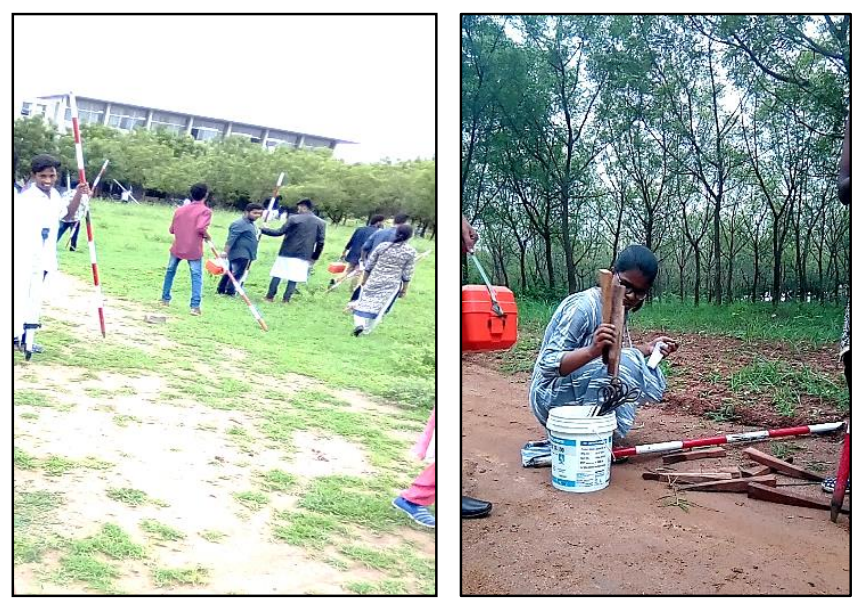

Fig. 1. Observations of students during Surveying

\section{b. Define}

Defining one's objective becomes very crucial at every point in Design Thinking. As the Problems are Versatile and Many in nature, all problems identified are analyzed and the following Needs and Challenges are Prioritized. In short Need Analysis is thoroughly done where qualitative data is converted to Quantitative (Metric) Data.

\section{i) Bench Marking}

Point of reference against which things may be compared. Eg - there should be some benchmarks chosen to prepare a product that could solve the problem to the higher extent. Seco Survey Kit, Sokkia Survey Kit, Baseline Pelican Tool Kit, Etc.,
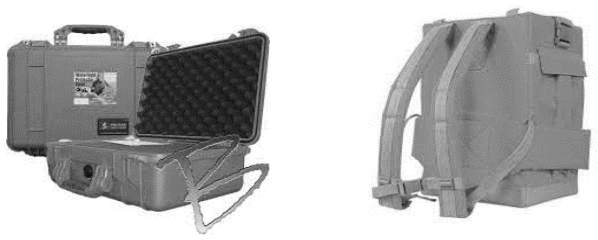

Fig. 2. Benchmark Existing Products

\section{ii) Need vs Metrics}

In order to convert the User needs into Engineering Specification, this tool is used.

\begin{tabular}{|c|c|c|c|c|c|c|}
\hline $\begin{array}{l}\text { Need/ } \\
\text { Metrix }\end{array}$ & Size & Shape & Weight & Strength & Friction & Thickness \\
\hline Handling & $\checkmark$ & $\sqrt{ }$ & $\checkmark$ & & $\checkmark$ & \\
\hline Durability & & & & $\checkmark$ & & \\
\hline Design & & $\checkmark$ & & & & \\
\hline Material & & & $\checkmark$ & $\checkmark$ & & $\checkmark$ \\
\hline
\end{tabular}

\section{iii) Preliminary Target Specification}

Once the needed parameters are known, Preliminary Targets are specified upon comparison with the benchmarks.

\begin{tabular}{|c|c|c|c|c|}
\multicolumn{2}{|c|}{ Table 3. Preliminary Target Specification } \\
\hline Metrics & Seco & Sokkia & $\begin{array}{c}\text { Baseline- } \\
\text { Pelican }\end{array}$ & $\begin{array}{c}\text { Preliminary } \\
\text { Target } \\
\text { Specification }\end{array}$ \\
\hline Dimension & $\begin{array}{c}\text { 24 Inch } \\
\text { Stake bag } \\
(61 \mathrm{~cm})\end{array}$ & $\begin{array}{c}24 \text { inch } \\
\text { with } 7 \\
\text { pockets }\end{array}$ & $\begin{array}{c}54.58 \\
\text { inches }\end{array}$ & 45 inches \\
\hline Material & $\begin{array}{c}\text { Rhinotech } \\
\text { material }\end{array}$ & Leather & $\begin{array}{c}\text { Metal Dry } \\
\text { Boxes }\end{array}$ & $\begin{array}{c}\text { Nylon grade } \\
\text { cloth }\end{array}$ \\
\hline Cost & $\begin{array}{c}62.00 \\
\text { dollars }\end{array}$ & $\begin{array}{c}39.20 \\
\text { dollars }\end{array}$ & $\begin{array}{c}97.95 \\
\text { dollars }\end{array}$ & $2500 /-$ \\
\hline Weight & $\begin{array}{c}0.8 \\
\text { pounds }\end{array}$ & $3 \mathrm{~kg}$ & $29 \mathrm{~kg}$ & $35 \mathrm{~kg}$ \\
\hline
\end{tabular}

\section{c. Ideate}

In the Ideation Phase, One shall make sense of what they have learned about the Need and identify opportunities for designing a Solution. In order to generate various concepts, many tools such as Mind Mapping, Morphological Chart, Bio mimics, Analogy, etc., are explored and as per the convenience one adopts. Once various concepts are generated selecting the best one out of them becomes a huge issue. Thus certain Tools like Six Thinking Hats, Weighted Matrix are used for Concept Selection.

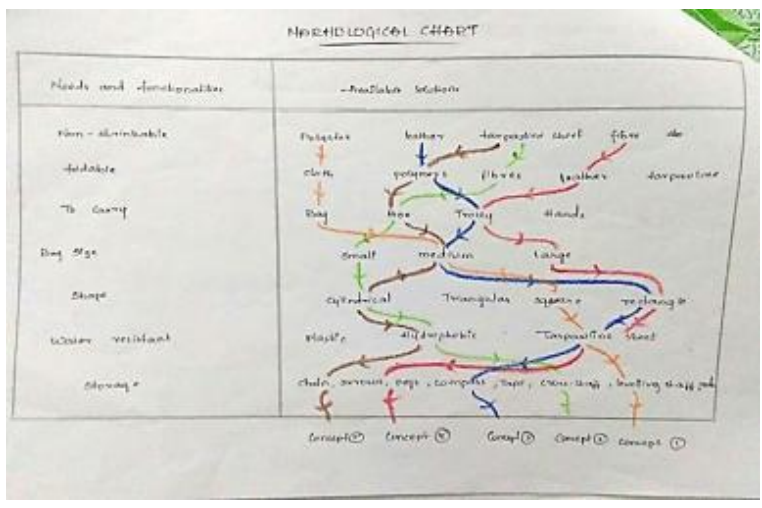

Fig. 3. Morphological Chart - Concept Generation 


\section{d. Prototype}

Once their Concept is ready and has detail sketches of their product, Many low fidelity Mock-up Models are Prepared. Also, storyboards are sketched and often they are encouraged to fail and iterate to understand the functional aspects of the Product. Later various tools and Labs are made available to build the product, Mostly Rapid Prototyping Labs and Product Design Studio [8], Tinkering Labs are made available.

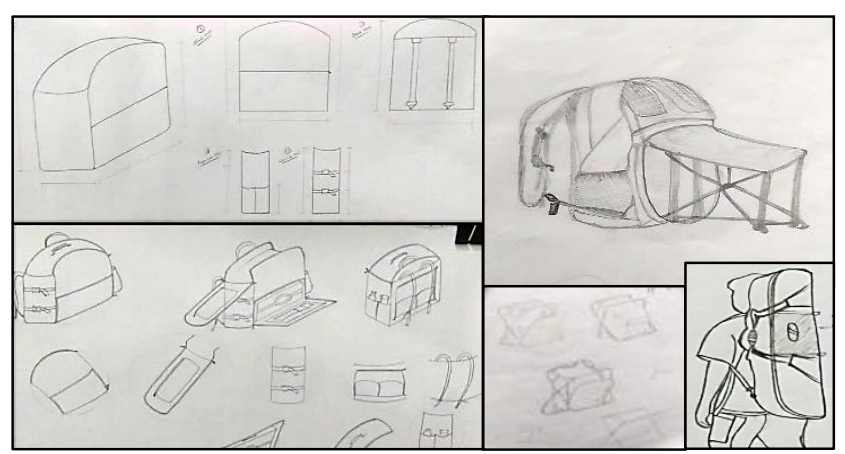

Fig. 4. Concept Sketching

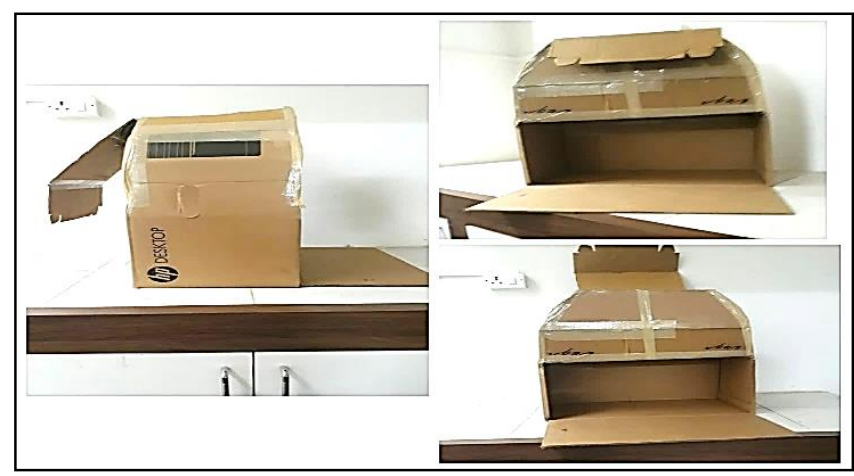

Fig. 5. Low Fidelity Mock-up Model

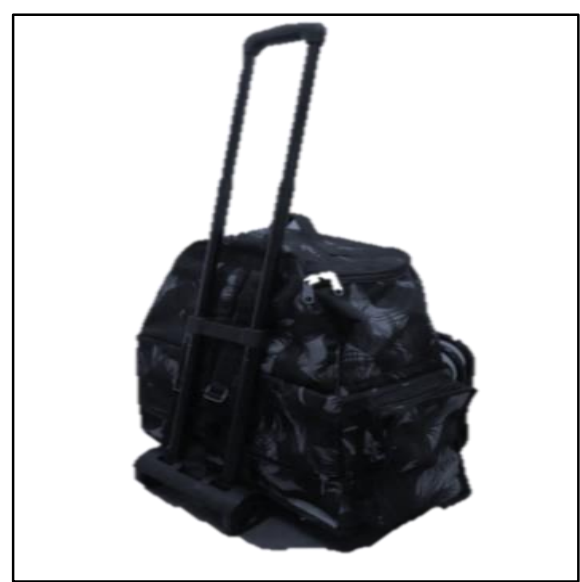

Fig. 6. Final Prototype - Surytroll (Survey Tool Carrier)

\section{e. Test}

As the products are User-Centric Designs, the users are encouraged to test over the Product to Criticize and Comment, give their Feedbacks so that they could re-iterate and make certain refinements. Once the beta prototype is ready, effective Pitching of their ideas is reciprocated over Entrepreneur Cells.

Ultimately the Products brought out are User-Centric, which work on a real-time basis and needful. This approach is taught with pure hands-on experience making students viable enough to understand the true nature of work in the future, giving practical Exposure [9]. The process could be put to their academics in various ways and they start using the tool effectively to come up with different Projects in their domains.

\section{Sample Students Work}

\section{A. SURVYTROLL}

Survytroll is Product Built upon understanding the needs of a surveyor who needs to carry various tools to perform topographical surveys. Since the tools are heavy to carry and multiple apparatus are required to be carried to the site from one place to another it becomes very difficult for surveyors to handle and carry the tools. The tropical climatic conditions make it even difficult. Understanding these needs students of the civil engineering department developed a concept to build a survey tool kit bag where all the tools can be properly organized and carried, either as a bag pack or like a trolley bag. They have also provided a portable stool for sitting at the site since the surveyor keeps on standing for a long time during work and could not find a place to sit which is painful indeed. The figure of the Product is shown in Fig. 6.

\section{B. EASETRAY}

Easetray is a modified serving tray which is built by the students in order to aid the waiters at the restaurant. The problem observed by the students was that the waiters were facing the difficulty while holding the serving tray in one hand and putting the vessels with the other hand. It was also observed that waiters kept their serving tray usually at another table to serve the food, so that, they could use their both hands to serve efficiently. By generating a Concept using Mind Mapping Tool, a modified serving tray was developed which enabled the waiters to carry the serving tray with minimal efforts using no hands. Also, the tray was designed with grooves and compartments to firmly hold the vessels.

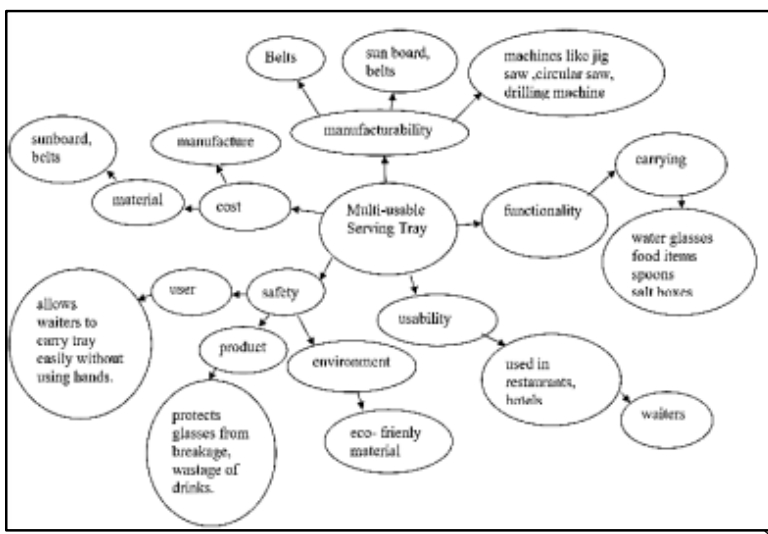


Fig. 7. Mind Mapping

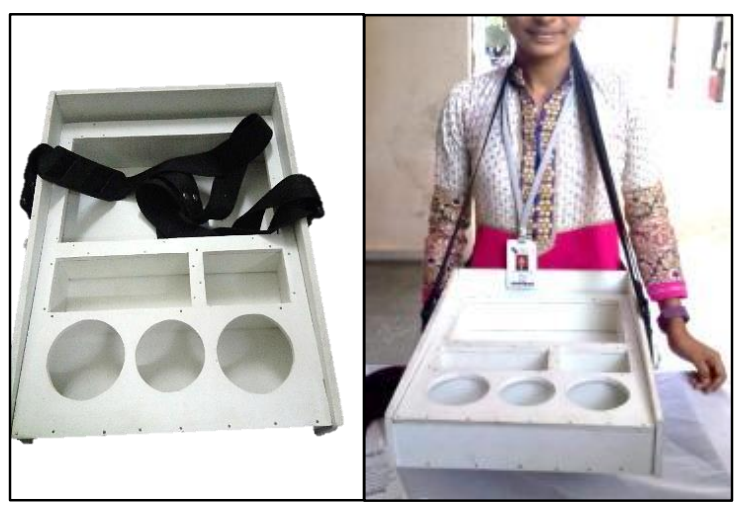

Fig. 8. Easetray (Serving Tray)

\section{Conclusion}

Incorporating Design Thinking in Engineering Education entails greater scope for engineering aspirants to understand the Global Problems and also understand the Engineering aspects by having a hands-on experience while Building the Product. Design thinking also provides a wider analogy and makes one think and question each and every task worked on. It also helps to attain the real-time objective of Engineering where students can cherish their future outcomes on par. Every year many Products are proposed and developed by students and are awarded accordingly based on their creativity, novelty, research and analysis and few other parameters. Almost 70\% of the Products developed are graded with merit grades and are further promoted for development. Few Projects are given some seed capital investment to enhance and upgrade their work. The strategic planning and sustainable approach along with a multidisciplinary integrated approach indeed protect the societies at large improving the Livelihood, Lifestyle thereby developing the Nation at once by developing our young engineer's perspective of learning.

\section{References}

[1] Govil Alok, T Anushalini, Sridhar Condoor, Effective Approach towards Development of Idea through Foundations to Product Design, Journal of Engineering Education Transformations, Volume 31, No. 3, January 2018, ISSN 2349-2473, eISSN 2394-1707

[2] Pothupogu Soumya, Govil Alok (2018), "Effective Approach Towards Elegant, Smart And Green City", International Journal of Civil Engineering and Technology, Volume 9, Issue 11, November 2018, pp. 2164-2169, ISSN Print: 0976-6308 and ISSN Online: 0976-6316.

[3] Jetti Rahul, Pothupogu Soumya, Govil Alok (2018), “A Smart and Sustainable Approach For Planning A Trenchant
Green City", International Journal of Civil Engineering and Technology, Volume 9, Issue 13, December 2018, pp. 705711, ISSN Print: 0976-6308 and ISSN Online: 0976-6316

[4] Bennett, A. G., Cassin, F., \& vandeer Merwe, M. (2017). How design education can use generative play to innovate for social change: A case study on the design of South African children's health education toolkits.International Journal of Design, 11(2), 57-72.

[5] Magno, M., Polonelli, T., Benini, L., \& Popovici, E. (2015). A Low Cost, Highly Scalable Wireless Sensor Network Solution to Achieve Smart LED Light Control for Green Buildings. IEEE Sensors Journal, 15(5), 2963-2973. DOI:10.1109/jsen.2014.2383996.

[6] B.Gopala Krishna Reddy, Y.Harsha, N.Lingeshwaran and SS.Asadi A Critical SWOT Analysis for Smart City Planning: A Model Study From Eluru City, International Journal of Civil Engineering and Technology. 8(4), 2017, pp.1506-1513.

[7] Chen, C. W. J., \& Lo, K. M. J. (2019). From TeacherDesigner to Student-Researcher: a Study of Attitude Change Regarding Creativity in STEAM Education by Using Makey Makey as a Platform for Human-Centred Design Instrument. Journal for STEM Education Research, 2(1), 75-91. DOI:10.1007/s41979-018-0010-6

[8] Kumar, K. S., Alok, G., Reddy, M. S., \& Reddy, N. C. S. (2018, November). An integrated Multidisciplinary skill development strategy for effective execution from virtuality to reality in Engineering Education. In 2018 IEEE 6th International Conference on MOOCs, Innovation and Technology in Education (MITE) (pp. 79-83). IEEE.

[9] Alok, G., Pothupogu, S., Reddy, M. S., \& SaiPriya, P. (2018, November). Trenchant Pathway to bring Innovation through Foundations to Product Design in Engineering Education. In 2018 IEEE 6th International Conference on MOOCs, Innovation and Technology in Education (MITE) (pp. 43-47). IEEE. 